\title{
Inhalation of Ultrafine and Fine Particulate Matter Disrupts Systemic Vascular Function
}

\author{
Kenneth W. Rundell \\ Marywood University, Scranton, Pennsylvania
}

Jay R. Hoffman

College of New Jersey, Trenton, New Jersey, USA

\author{
Renee Caviston, Ronald Bulbulian, and Amanda M. Hollenbach \\ Marywood University, Scranton, Pennsylvania
}

\begin{abstract}
This study investigated the effects of particulate matter (PM) with aerodynamic diameter 0.02$1 \mu \mathrm{m}$ (noted as $\mathrm{PM}_{1}$ ) inhalation during exercise on conduit artery and microvascular function. Inhalation of internal combustion-derived PM is associated with cardiovascular mortality and morbidity. Direct action of PM on the vascular endothelium is likely, as a substantial fraction of ultrafine PM translocates from the alveoli to the circulatory system. Sixteen intercollegiate athletes performed 30 min of exercise while inhaling low or high $\mathrm{PM}_{1}$. Flow-mediated brachial artery dilation (FMD) using high-resolution ultrasonography with simultaneous measurements of forearm oxygen kinetics using near infrared spectrophotometry (NIRS) was done before and after exercise. Basal brachial artery vasoconstriction was found after high $\mathbf{P M}_{1}$ exercise (4.0\%, $4.66 \pm 0.609$ to $4.47 \pm 0.625 \mathrm{~mm}$ diameter; $p=.0002)$, but not after low $\mathrm{PM}_{1}$ exercise $(-0.3 \%$, $4.66 \pm 0.626$ to $4.68 \pm 0.613 \mathrm{~mm}$ diameter). FMD was impaired after high $\mathrm{PM}_{1}$ exercise $(6.8 \pm$ $3.58 \%$ for preexercise FMD and $0.30 \pm 2.74 \%$ for postexercise FMD, $p=.0001$ ), but not after low $\mathrm{PM}_{1}$ exercise (6.6 \pm 4.04\% for preexercise FMD and $4.89 \pm 4.42 \%$ for postexercise $\left.\mathrm{FMD}\right)$. Reduction in forearm muscle reperfusion estimated by reoxygenation slope-to-baseline after 4 min cuff ischemia was observed for high $\mathrm{PM}_{1}$ exercise $(55 \%$ vs. 3\%, $p=.0006)$; no difference was noted for low $\mathbf{P M}_{1}$ exercise. Brachial artery FMD was significantly correlated to muscle reoxygenation slope-to-baseline $(r=.50, p=.005)$. Acute inhalation of high $\left[\mathrm{PM}_{1}\right]$ typical of urban environments impairs both systemic conduit artery function and microcirculation. The observed decrease reoxygenation slope-to-baseline after cuff release is consistent with reduced blood flow in the muscle microvasculature.
\end{abstract}

Increased hospital admissions for congestive heart failure, ischemic heart disease, and ischemic stroke have been associated with acute airborne particulate matter (PM) exposure (Dockery, 2001; Hoek et al., 2001; Peters et al., 2001). Inhalation of PM during exercise has been shown to cause decreased heart-rate variability (Magari, 2001; Pope et al., 1999) and ST-segment depression in patients with coronary heart disease (Pekkanen et al., 2002). Little direct in vivo evidence concerning precise mechanisms by which PM triggers these responses exists. How-

Received 20 July 2006; accepted 27 August 2006.

This study was funded by the American Heart Association (AHA), Pennsylvania Delaware Affiliate, award number 0455734U. The authors thank Scott Simmons, ultrasonographer, and Tina Evans, laboratory manager/technician, for their technical assistance.

Address correspondence to Kenneth W. Rundell, PhD, Professor of Health Science, College of Health and Human Services, Center for Healthy Families, Marywood University, 2300 Adams Avenue, Scranton, PA 18509, USA. E-mail: rundell@marywood.edu. ever, the inverse relationship between PM toxicity and particle diameter (Costa \& Dreher, 1997; Ferin et al., 1992; Oberdorster et al., 2004), and the rapid translocation of PM from lungs to systemic circulation supports a direct effect of PM on the vascular system.

Most studies documenting adverse health effects in relation to outdoor air pollutants have relied on measured concentrations from central monitoring stations, metrics of proximity to roads, or traffic volume estimates (Rundell et al., 2006; Zhu et al., 2002). Recent investigations support the notion that PM toxicity is highly influenced by number concentration and/or particle surface area (Oberdorster, 1996), and ambient particulate matter with median aerodynamic diameter less than $2.5 \mu \mathrm{m}$ $\left(\mathrm{PM}_{2.5}\right)$ has been associated with cardiovascular events (Burnett et al., 1995; Peters et al., 2001; Ware, 2000). The most common source of $\mathrm{PM}_{2.5}$ is combustion emissions of automobiles and diesel-powered trucks, with over $90 \%$ of the particle count from diesel aerosol having an aerodynamic diameter of $<30 \mathrm{~nm}$ 
(Kittelson et al., 2004). Recently, Kittelson et al. (2004) reported particle concentrations from multiple on-road aerosol measurements an order of magnitude higher than those typical of urban areas, with the average daily size ranging from 15 to $20 \mathrm{~nm}$. Using the Kittelson et al. (2004) mobile laboratory, Elder et al. (2004) identified significant PM effects on rat pulmonary and circulatory systems.

Inhalation of PM causes a systemic inflammatory response; Ulrich et al. (2002) reported a fourfold increase in tumor necrosis factor alpha (TNF- $\alpha$ ) levels in bronchial lavage fluid and a twofold increase in plasma endothelin-1 (ET-1) in PM-exposed rats. Bouthillier et al. (1998) found plasma ET-1 increased $15 \%$ in rats following inhalation of urban air PM. If the effect of these animal studies is similar in humans, then PM upregulation of ET-1 may play a key role in vascular pathology, since increased plasma ET-1 has a high predictive value for chronic heart failure and postmyocardial infarction mortality rate (Omland et al., 1994).

Diesel exhaust PM has been shown to suppress endotheliumdependent vasodilation via inhibition of nitric oxide (NO) release (Muto et al., 1996). Cheng and Kang (1999) found impaired vasorelaxation induced by acetylcholine from motorcycle gas engine exhaust particles, while Batalha et al. (2002) showed vasoconstriction of small pulmonary arteries in rats after inhalation of concentrated ambient particles. In a study using healthy human subjects, Brook et al. (2002) determined that short-term inhalation of concentrated ambient particles plus ozone caused acute conduit artery vasoconstriction but no change in flow-mediated vasodilation. O'Neill et al. (2005) reported that both flow-mediated and nitroglycerin-mediated vascular reactivity were decreased from polluted ambient air inhalation in type 2 diabetics. Likewise, impaired systemic endothelium-dependent dilation of the microcirculation has been shown in rats intratracheally instilled with residual oil fly ash (Nurkiewicz et al., 2004).

Endothelial function is commonly assessed by measuring the vasodilatory response to acetylcholine. Endothelium-dependent vasodilation is primarily regulated by NO, while ET-1 mediates artery vasoconstriction. Endothelial dysfunction leads to decreased bioavailability of NO and/or increased ET-1 (Puddu et al., 2000). Flow-mediated dilation (FMD) correlates highly with acetylcholine-induced vasodilation and has a strong positive predictive value (95\%) for coronary endothelial dysfunction (Anderson et al., 1995; Kang et al., 2002).

The effects of arteriolar blood flow dynamics on regional tissue oxygenation using near infrared spectroscopy (NIRS) have been studied in elite athletes (Foster et al., 1999; Im et al., 2001; Rundell et al., 1997) and intermittent claudicants (Seifalain et al., 2001). NIRS has been used to assess myocardial oxygenation in patients with ischemic heart disease during surgical revascularization (Perko \& Bay-Nielsen, 2002) and has been shown to be sensitive to cerebral artery and arteriole dysfunction (Terborg et al., 2002). The relationship between endothelial; function and muscle tissue oxygenation/hemodynamics using NIRS has not been established; however, local effects of arteriole endothelial dysfunction may be reflected in muscle reperfusion rate after artery occlusion.

Exercise upregulates endothelial cell nitric oxide synthase (eNOS) and superoxide dismutase (SOD), and enhances NOmediated arterial dilation (Laughlin et al., 2003). When blood flow in conduit arteries is increased, NO formation is stimulated, eliciting an endothelial-dependent vasodilatory response; the effect of PM inhalation on this process is not known. In this study, the effects of $\mathrm{PM}_{1}$ inhalation during exercise on flow-mediated dilation of the brachial artery and microcirculatory function in the forearm were evaluated. Correlations between brachial artery reactivity and muscle tissue oxygenation kinetics after high $\mathrm{PM}_{1}$ exposure exercise were established.

\section{METHODS}

Sixteen male intercollegiate athletes (age, $20.5 \pm 2.37 \mathrm{yr}$; weight, $79.8 \pm 9.63 \mathrm{~kg}$; height, $180 \pm 6.7 \mathrm{~cm}$; body mass index [BMI], $24.7 \pm 2.42$; mean $\pm \mathrm{SD}$ ) served as subjects. Subjects were nonasthmatic, nonsmokers, free of cardiovascular disease. All subjects signed a written informed consent. This study was approved by the Marywood University Institutional Review Board.

Subjects were instructed to abstain from caffeine ingestion for at least $24 \mathrm{~h}$ prior to testing and were required to report to the Human Performance Laboratory for testing at mid morning, $3 \mathrm{~h}$ after a light, low-fat breakfast. FMD of the brachial artery and NIRS of the flexor digitorum profundus muscle of the forearm were performed 10-20 min before and 20-30 min after each of 2 randomized exercise trials that were separated by 3 to 5 days. Exercise trials involved $30 \mathrm{~min}$ of running at between 85 and $90 \%$ of maximal heart rate; exercise intensity was verified using portable heart rate monitors (Polar Vantage XL, Polar Electro, Finland). Exercise was performed in ambient conditions either on an inner campus loop free of auto/truck traffic with low ambient particulate matter (aerodynamic diameter 0.02-1 $\mu \mathrm{m}\left[\mathrm{PM}_{1}\right]$; $5309 \pm 1942$ particles $\mathrm{cm}^{-3}$ ) or on a soccer field adjacent to a major highway with high ambient $\left[\mathrm{PM}_{1}\right](143,501 \pm 58,565$ particles $\mathrm{cm}^{-3}$ ).

Particulate matter $\left(\mathrm{PM}_{1}\right)$ was determined at each study site as previously done (Rundell, 2003). Measurements were made at $1.5 \mathrm{~m}$ height using a calibrated condensation particle counter (CPC, P-Trak ultrafine particle counter, model 8525,TSI, Inc., St. Paul, MN) at a sampling frequency of $1 \mathrm{~Hz}$ and recorded as 10 -s means of $\mathrm{PM}_{1} \mathrm{~cm}^{-3}$. Multiple readings were taken for each measurement and averaged to provide the most representative particle count for a specific measurement site. The P-Trak CPC sensitivity size range is $0.02-1.0 \mu \mathrm{m}$ diameter; this range includes ultrafine and fine $\mathrm{PM}$, defined as $\mathrm{PM}_{1}$ in this study. $\mathrm{PM}_{1}$ has been shown to account for $>90 \%$ of total particle count and $>95 \%$ of particle surface area $\left(\mu \mathrm{m}^{2} / \mathrm{cm}^{3}\right)$ for unit density mass concentration of combustion-derived air samples (Oberdorster et al., 1995). We have previously measured $\mathrm{PM}_{1}$ at this site over 62 days with daily mean concentrations of 115,000 to 134,000 
particles $\mathrm{cm}^{-3}$ (Rundell et al,. 2006). During all study trials, ambient $\mathrm{CO}$ was below 1.0 ppm, ambient $\mathrm{NO}_{2}$ was below 100 ppb, and ambient $\mathrm{O}_{3}^{-}$was below 0.10 ppm (GrayWolf Direct Sense TOX, Trumbull CT) at both low $\left[\mathrm{PM}_{1}\right]$ and high $\left[\mathrm{PM}_{1}\right]$ sites.

\section{Endothelial-Dependent FMD and NIRS Imaging}

Each subject was placed in a supine position on the exam table with the arm supported and immobilized in a Vac-Lok pillow (Medtech, Orange City, IA). Brachial artery FMD and forearm muscle microcirculation were assessed prior to and for 3 min after 4 min of artery occlusion, which was evoked using a sphygmomanometer cuff on the upper arm inflated to 280 $\mathrm{mm} \mathrm{Hg}$. The brachial artery was imaged above the antecubital fossa in the longitudinal plane using two-dimensional gray-scale imaging (Sonosite Titan, SonoSite, Inc. Bothell, WA). Images were captured at rest and at 40, 60, and 100 after cuff deflation. The average of four measurements at each time point image was used to derive the maximal FMD. FMD was expressed as a percentage of postocclusion vessel diameter relative to precuff occlusion vessel diameter.

Change in near-infrared light absorption by oxygenated and deoxygenated hemoglobin $(\mathrm{Hb})$ and myoglobin $(\mathrm{Mb})$ in the forearm muscle was evaluated using two-channel continuouswavelength NIRS at a sampling frequency of $4 \mathrm{~Hz}$ (cwNIRS; NIMS, Philadelphia, PA). The NIRS unit was fitted with a probe consisting of one LED (light-emitting diode) light source and two photodiode detectors. The optical probe was positioned on the medial aspect of the right forearm muscle. The location of the probe was recorded by noting distances from anatomical landmarks to ensure identical probe placement during all trials. Wavelengths of 730 and $850 \mathrm{~nm}$ were used to monitor relative change in oxy/deoxy-Hb/Mb. Oxy-Hb/Mb of muscle tissue was estimated by changes in the difference in signal strength at those wavelengths. Although individual contributions of $\mathrm{Hb}$ and $\mathrm{Mb}$ cannot be distinguished by NIRS because of similar absorption spectra for the respective oxygenated and deoxygenated chromophores, the contribution of myoglobin in skeletal muscle has been shown to account for less than $10 \%$ of the NIRS signal (Chance et al., 1988). Since $[\mathrm{Hb}]$ and $\left[\mathrm{HbO}_{2}\right]$ in large vessels are sufficient to maximally absorb NIR light, the signal reflects $\mathrm{Hb} / \mathrm{HbO}_{2}$ in muscle arterioles, capillaries, and venules (Mancini et al., 1994). Reperfusion rate after cuff ischemia following each session was computed as the slope of reoxygenation to baseline signal $\left(\mu M \mathrm{~s}^{-1} \mathrm{Hb}_{2}\right)$.

\section{Statistical Methods}

Vascular responses to high and low $\mathrm{PM}_{1}$ exposure and preand postcuff ischemia were compared using two-tailed paired $t$-tests. Pearson product moment correlation was used to evaluate the association between brachial artery FMD response to forearm muscle reoxygenation slope. A criterion alpha of $p \leq$ .05 was used to determine statistical significance. All data are reported as mean $\pm \mathrm{SD}$.

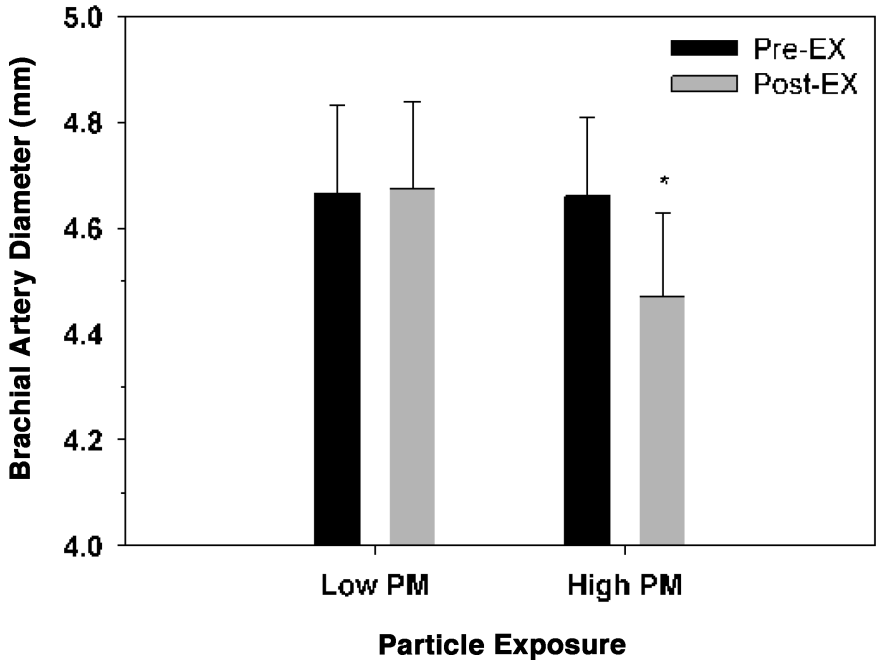

FIG. 1. Brachial artery diameter change before and after $30 \mathrm{~min}$ of exercise while breathing low or high $\left[\mathrm{PM}_{1}\right]$. High $\left[\mathrm{PM}_{1}\right]$ inhalation during exercise resulted in significant vasoconstriction ( $p=.0002)$. Pre-EX, preexposure; Post-EX, postexposure. Values presented as mean $\pm \mathrm{SE}$.

\section{RESULTS}

Basal brachial artery diameter changes from pre- to post- $\mathrm{PM}_{1}$ exercise exposures are depicted in Figure 1. High-resolution ultrasound measurements of the brachial artery diameter before and after $30 \mathrm{~min}$ of high $\left[\mathrm{PM}_{1}\right]$ exercise showed a statistically significant $4 \%$ vasoconstriction $(4.66 \pm 0.609 \mathrm{~mm}$ vs. $4.47 \pm$ $0.625 \mathrm{~mm}$, for pre- and postexposure exercise, respectively; $p=$ $.0002)$. No vasoconstriction was evident after $30 \mathrm{~min}$ of exercise in low $\left[\mathrm{PM}_{1}\right](4.66 \pm 0.626 \mathrm{~mm}$ vs. $4.68 \pm 0.613 \mathrm{~mm}$ diameter, for pre- and postexposure exercise, respectively). No difference between preexercise low $\left[\mathrm{PM}_{1}\right]$ and preexercise high $\left[\mathrm{PM}_{1}\right]$ basal brachial artery diameter was noted $(4.66 \pm 0.626$ $\mathrm{mm}$ vs. $4.66 \pm 0.609 \mathrm{~mm}$, respectively).

High $\mathrm{PM}_{1}$ inhalation during exercise resulted in a reduction in FMD (Figure 2). FMD was significantly impaired after $30 \mathrm{~min}$ of high $\left[\mathrm{PM}_{1}\right]$ exercise $(6.8 \pm 3.58 \%$ vs. $0.3 \pm 02.74 \%$ for pre- and postexercise measurements, respectively; $p=.0001)$. Under low $\left[\mathrm{PM}_{1}\right]$ conditions, preexercise FMD $(6.6 \pm 4.04 \%)$ and postexercise FMD $(4.9 \pm 4.42 \%)$ were not different. Post high $\left[\mathrm{PM}_{1}\right]$ exercise FMD was significantly less than pre and postlow $\left[\mathrm{PM}_{1}\right]$ exercise FMD $(p=.0001, p=.003$, respectively); preexercise high $\left[\mathrm{PM}_{1}\right]$ FMD was not different than preor postexercise $\left[\mathrm{PM}_{1}\right] \mathrm{FMD}$ values.

For low $\left[\mathrm{PM}_{1}\right]$ conditions, a nonsignificant 3\% reduction between pre- and postexercise forearm muscle NIRS reoxygenation slope-to-baseline after release of 4 min cuff ischemia was noted $\left(13.9 \pm 7.80 \mu \mathrm{Ms}^{-1}\right.$ vs. $13.5 \pm 7.44 \mu \mathrm{Ms}^{-1}$ for preexercise and postexercise, respectively; Figure 3 ). For high $\left[\mathrm{PM}_{1}\right]$ conditions, a significant $55 \%$ reduction between pre- and postexercise in NIRS reoxygenation slope-to-baseline after release of 4 min cuff ischemia was identified $\left(14.3 \pm 6.80 \mu \mathrm{Ms}^{-1}\right.$ vs. $6.4 \pm$ 


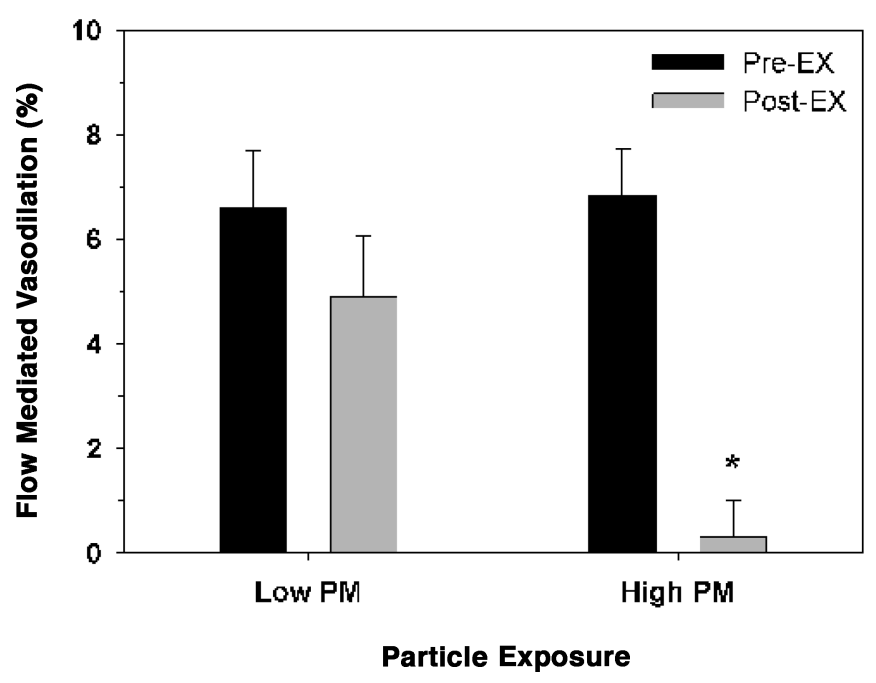

FIG. 2. Flow-mediated vasodilation of the brachial artery expressed as percent increase from basal diameter. Note the significantly blunted vasodilation after high $\left[\mathrm{PM}_{1}\right]$ exercise $(p=$ .0001). Pre-EX, preexposure, Post-EX, postexposure. Values presented as mean $\pm \mathrm{SE}$.

$3.55 \mu \mathrm{Ms}^{-1}$ for preexercise and postexercise, respectively; $p=$ .0006).

Brachial artery FMD response was significantly correlated to forearm muscle reoxygenation slope in pre- and postexercise under high $\left[\mathrm{PM}_{1}\right]$ conditions (Figure $4 ; R=.50, p=.005$ ). No significant correlation was found between brachial artery FMD response and forearm muscle reoxygenation slope to baseline in pre- and postexercise under low $\left[\mathrm{PM}_{1}\right]$.

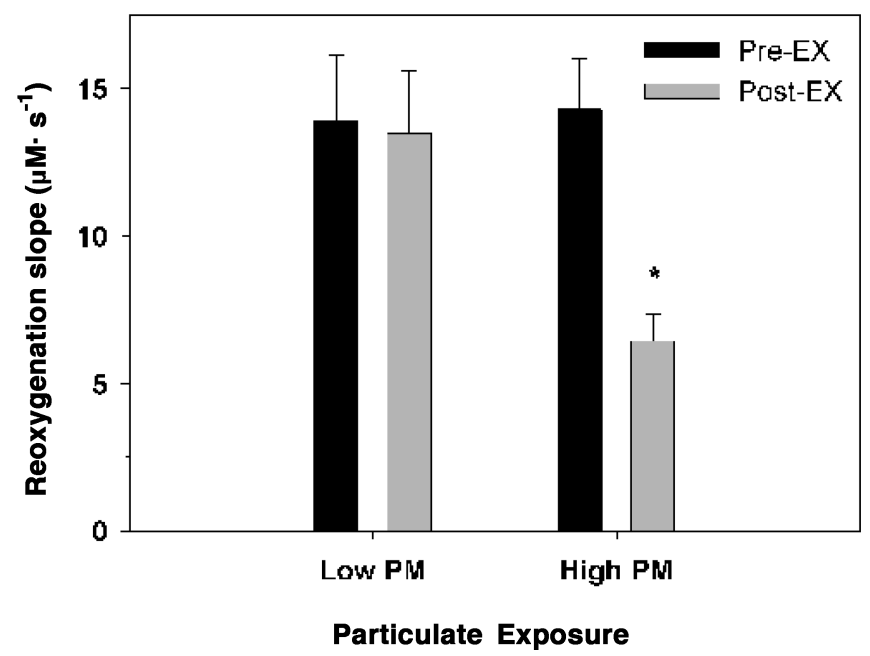

FIG. 3. Reperfusion slope to baseline of oxygenated hemoglobin $\left(\mu \mathrm{Ms}^{-1}\right)$ after 4 min of cuff ischemia. Note the significant $55 \%$ reduction in reperfusion slope after high $\left[\mathrm{PM}_{1}\right]$ exercise $(p=.0006)$. Pre-EX preexposure; Post-EX postexposure. Values presented as mean $\pm \mathrm{SE}$.

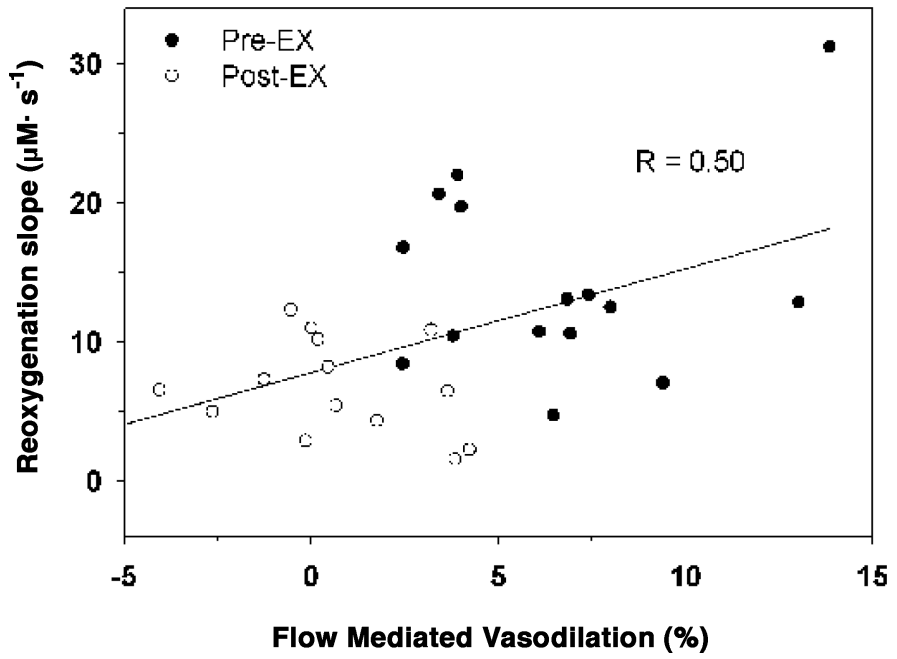

FIG. 4. A significant ( $p=.005$ ) correlation between reperfusion slope to baseline of oxygenated hemoglobin $\left(\mu M \mathrm{~s}^{-1}\right)$ and brachial artery FMD was found under high $\left[\mathrm{PM}_{1}\right]$ conditions. Filled circles represent preexposure (Pre-EX); open circles represent postexposure (Post-EX).

\section{DISCUSSION}

This study demonstrated adverse effects on conduit artery and microvascular functions after $\mathrm{PM}_{1}$ inhalation during 30 min of exercise. Consistent with Brook et al. (2002), significant vasoconstriction of the brachial artery after high $\left[\mathrm{PM}_{1}\right]$ exposure exercise, but not after low $\left[\mathrm{PM}_{1}\right]$ exposure exercise, was found. Our novel finding of diminished FMD after 30 min of high $\left[\mathrm{PM}_{1}\right]$ exercise suggests a $\mathrm{PM}_{1}$-induced disruption of normal endothelialmediated vasodilation. This observation is supported by the $55 \%$ decrease in the NIRS muscle reoxygenation slope-to-baseline after release of artery occlusion following high $\left[\mathrm{PM}_{1}\right]$ exposure exercise and is consistent with compromised reperfusion. We cannot determine with certainty whether the PM-induced reduction in NIRS reoxygenation slope was due to microcirculatory dysfunction, compromised brachial artery flow, or both. Fadel et al. (1996) found a strong correlation between brachial artery blood flow velocities with Doppler ultrasound and forearm tissue oxygenation with NIRS $(r=.80)$, suggesting that NIRS can reliably assess blood flow in the conduit arteries. In the present study, only $25 \%$ of the variability in NIRS reoxygenation slope was accounted for by brachial FMD, suggesting a constrictive response from $\mathrm{PM}_{1}$ inhalation in the microvasculature independent of the observed brachial artery vasoconstriction. This observation is critical to understanding the effects of $\mathrm{PM}_{1}$ inhalation on vascular dysfunction.

Epidemiological studies have defined strong links between ambient PM exposure and cardiac mortality and morbidity (Dockery, 2001; Hoek et al., 2001; Peters et al., 2001). Although the mechanism for PM-related systemic responses may originate through pulmonary production of inflammatory mediators (Salvi et al., 1999; van Eeden et al., 2001), translocation of particles to 
peripheral circulation has been recently demonstrated (Nemmar et al., 2001, 2002; Oberdorster et al., 1995). A rapid translocation of a substantial fraction of intratracheally instilled ${ }^{99 m} \mathrm{Tc}-$ albumin nanocolloid particles from the lungs into the systemic circulation has been observed in the hamster (Nemmar et al., 2001) and in humans (Nemmar et al., 2002). Nemmar et al. (2002) found that ${ }^{99 m}$ Tc ultrafine particles passed into the circulatory system within 1 min after inhalation, reached a peak concentration between 10 and $20 \mathrm{~min}$, and remained at this level for up to $60 \mathrm{~min}$. These studies support the presence of a pathway by which inhaled particles can have direct effects on vascular endothelium.

Respiratory number deposition fraction of ultrafine particles during exercise increases approximately $32 \%$ over resting values and exceeds predicted values for exercise by approximately $22 \%$ for 26-nm particles (Daigle et al., 2003). Total particle deposition increases approximately 4.5-fold for a 3.3-fold increase in minute ventilation (Daigle et al., 2003), and prediction models of particle deposition indicate that particles in the $30 \mathrm{~nm}$ size range are predominately deposited in airway generations 19-22 during exercise. Considering that greater than $90 \%$ of auto and truck emission particle number is found in the $3-30 \mathrm{~nm}$ size range and most of the particle mass is found in the $30-500 \mathrm{~nm}$ size range, particle deposition in the alveolar region is most likely high for individuals exercising in high auto emission conditions (ICRP, 1994). The probable high particle deposition in our high exposure treatment arm supports the observed PM-induced vascular effects.

Although U.S. Environmental Protection Agency (EPA) emission standards for particulate matter are based on mass metric, recent studies suggest that particle number and/or particle surface area are better related to emission inhalation health effects (Kittelson et al., 2004; Ramachandran et al., 2005). In this study, we chose to measure only particle number, since auto and diesel emission number deposition efficiency is much greater than on a mass basis (Daigle et al., 2003). Because we did not obtain particle size distributions for our number counts, we were unable to calculate a meaningful estimate of particle mass for comparisons.

The $4 \%$ vasoconstriction of the brachial artery after exercise while breathing high $\left[\mathrm{PM}_{1}\right]$ ambient air was consistent with the $\sim 2.6 \%$ vasoconstriction reported by Brook et al. (2002). The greater PM-induced vasoconstriction reported in the present study could be due to differences in study populations; our subjects were a homogeneous group of fit college athletes who were approximately $15 \mathrm{yr}$ younger than subjects in the Brook et al. (2002) study. Alternatively, particles in the Brook et al. (2002) study were concentrated $\mathrm{PM}_{2.5}$, while the particles in our study were freshly generated particles from auto/truck emissions with a predominant size range in the ultrafine and nano fraction. We have recently measured the rate of particle decay with distance from a major highway (Rundell et al., 2006). We cannot rule out the influence of ozone, as ozone exposure has been shown to increase rate-pressure product and heart rate after inhalation
(Gong et al., 1998). Although it is clear that vasoconstriction from particle inhalation occurs both in humans and in the animal model, it is not clear whether particles instill sympathetic nervous system activation, or create an inflammatory response with oxidative stress that causes an imbalance between vasoconstrictive and vasodilatory mediators. The acute $4 \%$ vasoconstriction does not seem large, and would be of little immediate consequence to healthy individuals; however, those individuals with cardiac risk factors could be more susceptible to myocardial ischemia from this vasoreactive response.

Significant correlations have been made between endothelial function and cardiovascular events, even after adjustment for other cardiac risk factors (Schachinger \& Zeiher, 2000) or in patients with no apparent obstructive coronary disease (Suwa et al., 2002). Diesel exhaust PM has been found to inhibit endotheliumdependent vasodilation via inhibition of NO release (Cheng \& Kang, 1999) and is cytotoxic to artery endothelial cells (Bai et al., 2001). In the present study, the abolishment of a flow-mediated dilatory response $(0.3 \pm 2.74 \%)$ following 4 min of upper arm ischemia after high $\left[\mathrm{PM}_{1}\right]$ exercise provides evidence for endothelial disruption in the conduit arteries from $\mathrm{PM}_{1}$ inhalation. The $6.6 \pm 4.06$ and $6.8 \pm 3.58 \%$ preexposure FMD values and the postexposure $4.9 \pm 4.42 \%$ low $\left[\mathrm{PM}_{1}\right]$ FMD is in agreement with other FMD measurements determined by upper arm occlusion. Agewall et al. (2001) reported greater dilation from upper arm occlusion than from lower arm occlusion (6.4\% vs. $3.9 \%)$; likewise, Berry et al. (2000) found greater brachial artery dilation after upper arm occlusion than after lower arm occlusion (9\% vs. 5.9\%). Incongruent with our results, Brook et al. (2002) found no change in FMD after inhalation of concentrated ambient $\mathrm{PM}_{2.5}$. The mean percent FMD values reported in that study were lower (range $3.57 \%$ to $4.52 \%$, for control and exposed) than our basal and low $\left[\mathrm{PM}_{1}\right]$ exposure FMD values. It was not reported whether upper or lower arm occlusion was used in the Brook et al. (2002) study, but if lower arm occlusion was used, then the basal FMD values would be in accord with our results.

The observation that motorcycle gas engine exhaust particles impaired vasorelaxation induced by acetylcholine (Cheng \& Kang, 1999) supports our results of impaired FMD, as acetylcholine-induced vasoconstriction correlates highly with FMD (Anderson et al., 1995; Kang et al., 2002). Nurkiewicz et al. (2004) found that residual oil fly ash (ROFA) abolished both NO-dependent and NO-independent systemic arteriolar dilation in the spinotrapezius muscle of rats. That group showed that approximately $50 \%$ of the arteriole vasoresponsiveness was due to NO-dependent factors. Since we did not evaluate nonendothelial dilation using sublingual nitroglycerine, we cannot dismiss the possibility that nonendothelial dilation contributed to our results.

In this study, the $55 \%$ reduction in NIRS reoxygenation slope to baseline after high $\left[\mathrm{PM}_{1}\right]$ exercise strongly suggests that the microcirculation is affected by $\mathrm{PM}_{1}$ inhalation. The fact that only $25 \%$ of the NIRS signal variability was accounted for by brachial artery FMD supports a vasoconstrictive response in the microcirculation from $\mathrm{PM}_{1}$ exposure. Since near- infrared 
light is differentially absorbed by oxygenated and deoxygenated hemoglobin and myoglobin (Chance et al., 1988), oxygen supply and demand to the muscle tissue are readily determined. Under steady-state conditions, change in NIRS signal should reflect blood flow and/or change in vascular tone in the arterioles. Calculation of the return slope of reoxygenation $\left(\mu M \mathrm{~s}^{-1}\right)$ to baseline after $4 \mathrm{~min}$ of cuff ischemia provides a rate of reperfusion of the muscle tissue that should be proportional to blood flow. These findings support a physiologically significant constriction and reduced blood flow in the microcirculation that could promote myocardial ischemia in individuals with cardiovascular disease.

\section{CONCLUSION}

This study identified acute effects on the systemic circulatory system after $\mathrm{PM}_{1}$ inhalation during exercise that could be an important component in explaining the reported increase in mortality and morbidity during and shortly after high PM exposure episodes. Complementary measurements of brachial artery function and muscle oxygen kinetics demonstrated that microcirculation (e.g., arterioles), as well as larger conduit arteries, are responsive to high-level $\mathrm{PM}_{1}$ exposure. A basal vasoconstrictive response as well as impaired FMD in the brachial artery was identified after exercise in high $\left[\mathrm{PM}_{1}\right]$, but not after exercise in low $\left[\mathrm{PM}_{1}\right]$. Using NIRS in the forearm before and after $\mathrm{PM}_{1}$ inhalation exercise, we found a decrease in the reperfusion slope after ischemia in the high $\left[\mathrm{PM}_{1}\right]$ exposure trials, suggesting compromised arteriolar flow. This novel finding is important since vascular dysfunction is associated with myocardial ischemia and is a hallmark of cardiovascular disease. Because fractional particle deposition during exercise increases almost twofold over resting deposition fraction, and total particle deposition is proportional to minute ventilation (Daigle et al., 2003), exercise in high PM environments could have long-term cardiovascular effects. Future studies need to examine chronic effects of high $\mathrm{PM}_{1}$ exposure and to identify the toxic factors in mixed PM.

\section{REFERENCES}

Agewall, S., Doughty, R. N., Bagg, W., Whalley, G. A., Braatvedt, G., and Sharpe, N. 2001. Comparison of ultrasound assessment of flowmediated dilatation in the radial and brachial artery with upper and forearm cuff positions. Clin. Physiol. 21:9-14.

Anderson, T. J., Uehata, A., Gerhard, M. D., Meredith, I. T., Knab, S., Delagrange, D., Lieberman, E. H., Ganz, P., Creager, M. A., and Yeung, A. C. 1995. Close relation of endothelial function in the human coronary and peripheral circulations. J. Am. Coll. Cardiol. 26:1235-1241.

Bai, Y., Suzuki, A. K., and Sagai, M. 2001. The cytotoxic effects of diesel exhaust particles on human pulmonary artery endothelial cells in vitro: Role of active oxygen species. Free Radical. Biol. Med. 30:555-562.

Batalha, J. R., Saldiva, P. H., Clarke, R. W., Coull, B. A., Stearns, R. C., Lawrence, J., Murthy, G. G., Koutrakis, P., and Godleski,
J. J. 2002. Concentrated ambient air particles induce vasoconstriction of small pulmonary arteries in rats. Environ. Health Perspect. 110:1191-1197.

Berry, K. L., Skyrme-Jones, R. A., and Meredith, I. T. 2000. Occlusion cuff position is an important determinant of the time course and magnitude of human brachial artery flow-mediated dilation. Clin. Sci. (Lond.) 99:261-267.

Bouthillier, L., Vincent, R., Goegan, P., Adamson, and I. Y., Bjarnason, S., Stewart, M., Guenette, J., Potvin, M., Kumarathasan, P. 1998. Acute effects of inhaled urban particles and ozone: Lung morphology, macrophage activity, and plasma endothelin-1. Am. J. Pathol. 153:1873-1884.

Brook, R. D., Brook, J. R., Urch, B., Vincent, R., Rajagopalan, S., and Silverman, F. 2002. Inhalation of fine particulate air pollution and ozone causes acute arterial vasoconstriction in healthy adults. Circulation 105:1534-1536.

Burnett, R. T., Dales, R., Krewski, D., Vincent, R., Dann, T., and Brook, J. R. 1995. Associations between ambient particulate sulfate and admissions to Ontario hospitals for cardiac and respiratory diseases. Am. J. Epidemiol. 142:15-22.

Chance, B., Nioka, S., Kent, J., McCuly, K., Fountain, M., Greenfeld, R., and Holtom, G. 1988. Time-resolved spectroscopy of hemoglobin and myoglobin in resting and ischemic muscle.Anal. Biochem. 174:698-707.

Cheng, Y. W., and Kang, J. J. 1999. Inhibition of agonist-induced vasocontraction and impairment of endothelium-dependent vasorelaxation by extract of motorcycle exhaust particles in vitro. J. Toxicol. Environ. Health A 57:75-87.

Costa, D. L., and Dreher, K. L. 1997. Bioavailable transition metals in particulate matter mediate cardiopulmonary injury in healthy and compromised animal models. Environ. Health Perspect. 105(Suppl. 5):1053-1060.

Daigle, C. C., Chalupa, D. C., Gibb, F. R., Morrow, P. E., Oberdorster, G., Utell, M. J., and Frampton, M. W. 2003. Ultrafine particle deposition in humans during rest and exercise. Inhal. Toxicol. 15:539-552.

Dockery, D. W. 2001. Epidemiologic evidence of cardiovascular effects of particulate air pollution. Environ. Health Perspect. 109(suppl. 4):483-486.

Elder, A., Gelein, R., Finkelstein, J., Phipps, R., Frampton, M., Utell, M., Kittelson, D. B., Watts, W. F., Hopke, P., Jeong, C. H., Kim, E., Liu, W., Zhao, W., Zhuo, L., Vincent, R., Kumarathasan, P., and Oberdorster, G. 2004. On-road exposure to highway aerosols. 2. Exposures of aged, compromised rats. Inhal. Toxicol. (16 suppl. 1):4153.

Fadel, P. J., Keller, D. M., Watanabe, H., Raven, P. B., and Thomas, G. D. 1996. Noninvasive assessment of sympathetic vasoconstriction in human and rodent skeletal muscle using near-infrared spectroscopy and Doppler ultrasound. J. Appl. Physiol. 96:1323-1330.

Ferin, J., Oberdorster, G., and Penney, D. P. 1992. Pulmonary retention of ultrafine and fine particles in rats. Am. J. Respir. Cell Mol. Biol. 6(5):535-542.

Foster, C., Rundell, K. W., Snyder, A. C., Stray-Gunderson, J., Kempers, G., Thometz, N., Broker, J., Broshears, C., Hill, J., Knapp, E., Matiasek, M., and Niak, J. 1999. Evidence for restricted muscle blood flow during speed skating. Med. Sci. Sports Exerc. 31:14331440 .

Gong, H. Jr., Wong, R., Sarma, R. J., Linn, W. S., Sullivan, E. D., Shamoo, D. A., Anderson, K. R., and Prasad, S. B. 1998. Relationship 
between acute ozone responsiveness and chronic loss of lung function in residents of a high-ozone community. Arch. Environ. Health 53:313-319.

Hoek, G., Brunekreef, B., Fischer, P., and van Wijnen, J. 2001. The association between air pollution and heart failure, arrhythmia, embolism, thrombosis, and other cardiovascular causes of death in a time series study. Epidemiology 12:355-357.

Im, J., Nioka, S., Chance, B., and Rundell, K. W. 2001. Muscle oxygen desaturation is related to whole body $\mathrm{VO}_{2}$ during cross-country skiing. Int. Nat. J. Sport Med. 22:356-360.

International Commission on Radiological Protection. 1994. Human Respiratory Tract Model for Radiological Protection. ICRP Publication No. 66. Tarrytown, NY: Elsevier Science Ltd.

Kang, S. M., Chung, N., Kim, J. Y., Koo, B. K., Choi, D., Jang, Y., and Cho, S. Y. 2002. Relation of vasodilator response of the brachial artery to inflammatory markers in patients with coronary artery disease. Echocardiography. 19:661-667.

Kittelson, D. B., Watts, W. F., Johnson, J. P., Remerowki, M. L., Ische, E. E., Oberdorster, G., Gelein, R. M., Elder, A., Hopke, P. K., Kim, E., Zhao, W., Zhou, and L., Jeong, C. H. 2004. On-road exposure to highway aerosols. 1. Aerosol and gas measurements. Inhal. Toxicol. 16(suppl. 1):31-39.

Laughlin, M. H., Rubin, L. J., Rush, J. W., Price, E. M., Schrage, W. G., and Woodman, C. R. 2003. Short-term training enhances endothelium-dependent dilation to coronary arteries, not arterioles. J. Appl. Physiol. 94:234-244.

Magari, S. R., Hauser, R., Schwartz, J., Williams, P. L., Smith, T. J., and Christiani, D. C. 2001. Association of heart rate variability with occupational and environmental exposure to particulate air pollution. Circulation 104:986-991.

Mancini, D. M., Bolinger, L., Li, H., Kendrick, K., Chance, B., and Wilson, J. R. 1994. Validation of near-infrared spectroscopy in humans. J. Appl. Physiol. 77:2740-2747.

Muto, E., Hayashi, T., Yamada, K., Eski, T., Sagai, M., and Lguchi, A. 1996. Endothelial-constitutive nitric oxide synthase exists in airways and diesel exhaust particles inhibit the effect of nitric oxide. Life Sci. 59:1563-1570.

Nemmar, A., Vanbilloen, H., Hoylaerts, M. F., Hoet, P. H. M., Verbruggen, A., and Nemery, B. 2001. Passage of intratracheally instilled ultrafine particles from the lung into the systemic circulation in hamster. Am. J. Respir. Crit. Care Med. 164:1665-1668.

Nemmar, A., Hoet, P. H. M., Vanquickenborne, B., Dinsdale, D., Thomeer, M., Hoyalaerts, M. F., Vanbiloen, H., Mortelmans, L., and Nemery, B. 2002. Passage of inhaled particles into the blood circulation in humans. Circulation 105:411-414.

Nurkiewicz, T. R., Porter, D. W., Barger, M., Castranova, V., and Boegehold, M. A. 2004. Particulate matter exposure impairs systemic microvascular endothelium-dependent dilation. Environ. Health Perspect. 112:1299-1306.

Oberdorster, G. 1996. Significance of particle parameters in the evaluation of exposure-dose-response relationships of inhaled particles. Inhal. Toxicol. 8(suppl. 1):73-89.

Oberdorster, G., Gelein, R. M., Ferin, J., and Weiss, B. 1995. Association of particulate air pollution and acute morbidity: Involvement of ultrafine particles? Inhal. Toxicol. 7:111-124.

Oberdorster, G., Sharp, Z., Atudorei, V., Elder, A., Gelein, R., Kreyling, W., and Cox, C. 2004. Translocation of inhaled ultrafine particles to the brain. Inhal. Toxicol. 16:437-445.
Omland, T., Lie, R. T., Aakvaag, A., Aarsland, T., and Dickstein, K. 1994. Plasma endothelin determination as a prognostic indicator of 1-year mortality after acute myocardial infarction. Circulation. 89:1573-1579.

O’Neill, M. S., Veves, A., Zanobetti, A., Sarnat, J. A., Gold, D. R., Economides, P. A., Horton, E. S., and Schwartz, J. 2005. Diabetes enhances vulnerability to particulate air pollution-associated impairment in vascular reactivity and endothelial function. Circulation 111:2913-2920.

Pekkanen, J., Peters, A., Hoek, G., Tiittanen, P., Brunekreef, B., de Hartog, J., Heinrich, J., Ibald-Mulli, A., Kreyling, W. G., Lanki, T., Timonen, K. L., and Vanninen, E. 2002. Particulate air pollution and risk of ST-segment depression during repeated submaximal exercise tests among subjects with coronary heart disease: The exposure and risk assessment for fine and ultrafine particles in ambient air (ULTRA) study. Circulation 106:890-892.

Perko, M. J., and Bay-Nielsen, H. 2002. Regional myocardial oxygenation during surgical revascularisation. Cardiovasc. Surg. 10:590594.

Peters, A., Dockery, D. W., Muller, J. E., and Mittleman, M. A. 2001. Increased particulate air pollution and the triggering of myocardial infarction. Circulation 103:2810-2815.

Pope, C. A. 3rd, Verrier, R. L., Lovett, E. G., Larson, A. C., Raizenne, M. E., Kanner, R. E., Schwartz, J., Villegas, G. M., Gold, D. R., and Dockery, D. W. 1999. Heart rate variability associated with particulate air pollution. Am. Heart J. 138:804-807.

Puddu, P., Puddu, G. M., Zaca, F., and Muscari, A. 2000. Endothelial dysfunction and hypertension. Acta Cardiol. 55:221-232.

Ramachandran, G., Paulsen, D., Watts, W., and Kittelson, D. 2005. Mass, surface area and number metrics in diesel occupational exposure assessment. J Environ Monit. 7(7):728-735.

Rundell, K. W. 2003. High levels of airborne ultrafine and fine particulate matter in indoor ice arenas. Inhal. Toxicol. 15:237250.

Rundell, K. W., Nioka, S., and Chance, B. 1997. Hemoglobin/ myoglobin desaturation during speed skating. Med. Sci. Sports Exercise 29:248-258.

Rundell, K. W., Caviston, R., Hollenbach, A. M., and Murphy, K. 2006. Vehicular air pollution, playgrounds, and youth athletic fields. Inhal. Toxicol. 18:541-547.

Salvi, S., Blomberg, A., Rudell, B., Kelly, F., Sandstrom, T., and Holgate, S. T., Frew, A. 1999. Acute inflammatory responses in the airways and peripheral blood after short-term exposure to diesel exhaust in healthy human volunteers. Am. J. Respir. Crit. Care Med. 159:702-709.

Schachinger, V., and Zeiher, A. M. 2000. Atherosclerosis-associated endothelial dysfunction. Z. Kardiol. 89(suppl. 9):IX/70-74.

Seifalain, A. M., Atwal, A., White, S., Mikhailidis, D. P., Baker, D., and Hamilton, G. 2001. A role for near infrared spectroscopy in the assessment of intermittent claudication. Int. Angiol. 20:301306.

Suwa, T., Hogg, J. C., Quinlan, K. B., Obgami, A., Vincent, R., and van Eeden, S. F. 2002. Particulate air pollution induces progression of atherosclerosis. J. Am. Coll. Cardiol. 39:943-945.

Terborg, C., Bramer, S., Weiller, C., and Rother, J. 2002. Short-term effect of cigarette smoking on $\mathrm{CO}_{2}^{-}$induced vasomotor reactivity in man. A study with near-infrared spectroscopy and transcranial Doppler sonography. J. Neurol. Sci. 205:15-20. 
Ulrich, M. M., Alink, G. M., Kumarathasan, P., Vincent, R., Boere, A. J., and Cassee, F. R. 2002. Health effects and time course of particulate matter on the cardiopulmonary system in rats with lung inflammation. J. Toxicol. Environ. Health A 65:1571-1595.

van Eeden, S. F., Tan, W. C., Suwa, T., Mukae, H., Terashima, T., Fujii, T., Qui, D., Vincent, R., and Hogg, J. C. 2001. Cytokines involved in the systemic inflammatory response induced by exposure to particulate matter air pollutants $\left(\mathrm{PM}_{10}\right)$. Am. J. Respir. Crit. Care Med. 164:826-830.

Ware, J. H. 2000. Particulate air pollution and mortality-clearing the air. N. Engl. J. Med. 343:1798-1799.

Zhu, Y., Hinds, W. C., Seongheon, K., and Sioutas, C. 2002. Concentration of ultrafine particles near a major highway. J. Air Waste Manage. Assoc. 52:1032-1042. 